\title{
Transient Elevation of Granulocyte Colony-Stimulating Factor Levels in Cerebrospinal Fluid at the Initial Stage of Aseptic Meningitis in Children
}

\author{
KEITARO FUKUSHIMA, AKIRA ISHIGURO, AND TOSHIKAZU SHIMBO
}

Department of Pediatrics, Mizonokuchi Hospital, Teikyo University School of Medicine, Kawasaki, Japan

\section{ABSTRACT}

\begin{abstract}
At the early stage of aseptic meningitis, there is a transient increase in neutrophil counts in the cerebrospinal fluid. Some factors in the cerebrospinal fluid might induce migration of neutrophils into the cerebrospinal fluid. Granulocyte colony-stimulating factor (GCSF) plays an important role, not only as a hemopoietic factor but also as a regulating factor for a biologic defense system by neutrophils in the foci of infection. To analyze the role of G-CSF on accumulating neutrophils in the cerebrospinal fluid, we have measured G-CSF levels in the cerebrospinal fluid of children with aseptic meningitis, paying particular attention to the phasal transition. Within the first $2 \mathrm{~d}$ from the onset, G-CSF levels in the cerebrospinal fluid were $223 \pm 97 \mathrm{ng} / \mathrm{L}$, significantly higher than those of the patients without meningitis $(p<0.01)$. Beyond the second day after the onset, the G-CSF levels rapidly decreased to below the detectable level, even though the patients manifested meningeal signs and symptoms. There was a direct relationship
\end{abstract}

between G-CSF levels and neutrophil counts in the cerebrospinal fluid $(r=0.763, p<0.01)$. During the first $2 \mathrm{~d}$ after the onset, the G-CSF level in the cerebrospinal fluid in each case was remarkably higher than that in the serum. This finding suggests that the G-CSF in the cerebrospinal fluid was produced in the spinal cavity. From our results, the transient elevation of G-CSF levels might lead to the transient increase in neutrophil counts in the cerebrospinal fluid by recruiting them from the peripheral blood at the initial stage of aseptic meningitis. (Pediatr Res 37: 160-164, 1995)

CSF, colony-stimulating factor

\section{Abbreviations}

G-CSF, granulocyte colony-stimulating factor

rhG-CSF, recombinant human G-CSF

GM-CSF, granulocyte-macrophage colony-stimulating factor IFN, interferon
Aseptic meningitis is characterized by an increase in mononuclear cells in the cerebrospinal fluid. However, at the early stage of the disease, the cerebrospinal fluid temporarily contains chiefly neutrophils (1). The pathogenesis of the increase in neutrophils in the cerebrospinal fluid remains unclear. Some factors in the cerebrospinal fluid might induce migration of neutrophils into the cerebrospinal fluid at the early stage of the disease.

G-CSF was found as a factor that stimulates the proliferation of precursor cells, specifically for granulocytic lineage (2-4). This cytokine acts not only on progenitor cells of granulocytic lineage but also directly on mature neutrophils (5-8). G-CSF activates the functions of mature neutrophils, including $\mathrm{C} 3 \mathrm{bi}$ receptor expression $(9)$, adherence $(9,10)$, superoxide release $(11,12)$, phagocytosis (13), antibody-dependent cell-mediated cytotoxicity $(14,15)$, and chemotactic activity (16); it also prolongs survival time $(17,18)$. Serum G-CSF levels have been

Received February 25, 1994; accepted August 23, 1994.

Correspondence: Toshikazu Shimbo, M.D., Ph.D., Department of Pediatrics, Mizonokuchi Hospital, Teikyo University, School of Medicine, 74 Mizonokuchi, Takatsu, Kawasaki, 213, Japan.

Supported in part by a grant in aid for Fundamental Scientific Research from the Education Ministry of Japan (No. 05770562). reported to elevate in many inflammatory diseases, with an increase of neutrophils in the peripheral blood $(19,20)$. Therefore, G-CSF plays an important role, not only as a hemopoietic factor but also as a regulating factor for a biologic defense system in the foci of both infection and inflammation $(21,22)$. G-CSF might be involved in the development of inflammation in the focus by the activation of mature neutrophils. However, little is known about G-CSF levels in inflammatory foci such as synovia, pleural fluid, and cerebrospinal fluid.

To analyze the role of G-CSF in accumulating neutrophils in the cerebrospinal fluid during the early stage of aseptic meningitis, we have measured G-CSF levels in the cerebrospinal fluid of children with the disease. This work has demonstrated that G-CSF levels in the cerebrospinal fluid are markedly elevated in the acute phase of the illness.

\section{METHODS}

Study population. Fourteen patients with aseptic meningitis, ranging in age from 4 mo to $15 \mathrm{y}$, were admitted to our hospital from June to October 1991. The following criteria were used for the diagnosis of aseptic meningitis: 1) all of the following 
symptoms: fever, headache, vomiting, and neck stiffness; 2) cell counts greater than 35 per $\mu \mathrm{L}$ in the cerebrospinal fluid; and 3 ) sterile cerebrospinal fluid found in bacteriologic studies. The first day of the illness was determined as the day when any of the symptoms of meningitis had first occurred. The following criteria were used for the diagnosis of no meningitis: 1 ) cell counts less than 5 per $\mu \mathrm{L}$ in the cerebrospinal fluid, and 2) sterile cerebrospinal fluid found in bacteriologic studies. Patients meeting these criteria were used as controls. The patients without meningitis included three with meningism due to upper respiratory tract infections, two with epilepsy, two with acute gastroenteritis, and one with febrile convulsions. They all received lumbar punctures to rule out meningitis. Table 1 shows the characteristics of 14 patients with aseptic meningitis and eight who did not have meningitis. The age, sex, and concentration of glucose in the cerebrospinal fluid in both groups were statistically similar. The protein values in the cerebrospinal fluid of the patients with meningitis were not significantly different from those of the group without meningitis. Some of the meningitis patients had elevations of protein values, but none of the patients without meningitis did.

Viral study. In the summer of 1991, a prevalence of echovirus 30 caused endemic aseptic meningitis. Serum antibodies for anti-echovirus 30 were examined by a serum neutralization test in pairs of samples collected 2 to $3 \mathrm{wk}$ apart. In six of nine patients studied, the antibody titer rose four times or more. Furthermore, in three patients with meningitis and four patients without meningitis, viruses isolated from the cerebrospinal fluid were studied by using tissue culture microplates containing cynomolgus monkey kidney, Vero, and HeLa cells (22a). The isolated virus was determined by the neutralizing test with standard antivirus serum. In all three patients with meningitis studied, echovirus 30 was isolated, but in all four patients without meningitis studied, no virus was isolated. Therefore, it seems that the illness was caused by echovirus 30 in most of the patients with meningitis.

Sample collection. Samples of the cerebrospinal fluid were obtained by lumbar puncture after receiving informed consent for this study from the parents of the patients. The cerebrospinal fluid was immediately centrifuged at $150 \times g$ for $10 \mathrm{~min}$, and the supernatant was stored at $-30^{\circ} \mathrm{C}$. Blood samples were collected at the same time. Sera were isolated by centrifugation at $400 \times g$ for $10 \mathrm{~min}$ and stored at $-30^{\circ} \mathrm{C}$.

Assay for G-CSF . Concentrations of G-CSF were measured by a subsequent ELISA. The assay was based on the dual antibody immunometric sandwich method, as previously described (23). Rabbit antiserum against rhG-CSF (Chugai Pharmaceuticals, Tokyo, Japan) (24) was precipitated with ammonium sulfate. The precipitate was dissolved in $0.05 \mathrm{M}$ borate- buffered saline containing $0.9 \% \mathrm{NaCl}(\mathrm{BBS})(\mathrm{pH} 8.0)$ and fractionated to $\mathrm{IgG}$ by Ultrogel AcA44 gel filtration (LKB, Stockholm, Sweden). Polystyrene tubes (Nunc, Roskilde, Denmark) were coated with BBS containing $20 \mathrm{mg} / \mathrm{L} \mathrm{IgG}$ for $16 \mathrm{~h}$ at $4^{\circ} \mathrm{C}$. The coating solution was removed by aspiration, and the tubes were washed twice with BBS. Each $0.2-\mathrm{mL}$ aliquot and standard rhG-CSF was dispensed into the tubes diluted with $0.5 \mathrm{~mL}$ of $0.05 \mathrm{M}$ Tris- $\mathrm{HCl}$ buffer ( $\mathrm{pH} \mathrm{8.0)}$ containing $0.25 \%$ BSA, $0.05 \%$ Tween $20,2 \%$ polyethylene glycol, $0.9 \%$ $\mathrm{NaCl}$, and $0.1 \% \mathrm{NaN}_{3}$. The tubes were incubated for $2 \mathrm{~h}$ at room temperature and washed three times with $20 \mathrm{mM}$ Tris$\mathrm{HCl}$ buffer. The tubes were filled with horseradish peroxidaselabeled anti-rhG-CSF rabbit Fab' (Chugai Pharmaceuticals, Tokyo, Japan), incubated for $2 \mathrm{~h}$ at room temperature, and washed three times. The tubes were filled with $1 \mathrm{~mL}$ of substrate solution consisting of $0.1 \mathrm{M}$ phosphate citrate buffer ( $\mathrm{pH}$ 6.0), 0.015\% hydrogen peroxide, and $3 \mathrm{~g} / \mathrm{L}$ o-phenylene diamine (Nakarai Chemicals, Kyoto, Japan). After $1 \mathrm{~h}$ of incubation at room temperature in the dark, the enzyme reaction was stopped with $1 \mathrm{~mL}$ of $4 \mathrm{~N} \mathrm{H}_{2} \mathrm{SO}_{4}$, and each sample was measured for adsorbance at $492 \mathrm{~nm}$ in duplicate. The limit of detection was $30 \mathrm{ng} / \mathrm{L}$. This assay system did not react with macrophage-CSF, GM-CSF, or IL-3.

Statistical analysis. Statistical significance of the data was analyzed with the Mann-Whitney $U$ test. The relationships between cerebrospinal G-CSF levels and other indices of meningeal inflammation were estimated by Pearson's correlation coefficients. Differences were considered significant when the $p$ value was less than 0.05 .

\section{RESULTS}

G-CSF levels in cerebrospinal fluid. Concentrations of G-CSF were assayed within the first $2 \mathrm{~d}$ from the onset of aseptic meningitis in nine patients (Fig. 1), and the values were $223 \pm 97 \mathrm{ng} / \mathrm{L}$ (mean $\pm \mathrm{SD}$, range 53 to $386 \mathrm{ng} / \mathrm{L}$ ). These levels were significantly higher $(p<0.01)$ than those of the children with no meningitis (all were less than $30 \mathrm{ng} / \mathrm{L}$ ). The anti-echovirus 30 antibody titer rose 4 times or more in six patients but not in three patients. The G-CSF levels in the former were $217 \pm 59 \mathrm{ng} / \mathrm{L}$ and those in the latter were $235 \pm$ $169 \mathrm{ng} / \mathrm{L}$. These values were not statistically significant. Figure 2 illustrates time-dependent changes in G-CSF levels in the cerebrospinal fluid. After the second day of the onset of the disease, the G-CSF values rapidly decreased to below the detectable level, even though the patients manifested meningeal symptoms and signs: fever, headache, vomiting, and neck stiffness. The G-CSF levels sequentially dropped in all patients examined longitudinally, as shown in Figure 2. G-CSF levels

Table 1. Characteristics of study population

\begin{tabular}{|c|c|c|c|c|c|}
\hline & \multicolumn{2}{|c|}{ Age (y) } & \multirow{2}{*}{$\begin{array}{c}\operatorname{Sex} \\
(\mathrm{M} / \mathrm{F})\end{array}$} & \multirow{2}{*}{$\begin{array}{l}\text { Total protein in } \\
\frac{\mathrm{CSF}^{*}(\mathrm{~g} / \mathrm{L})}{\text { Mean } \pm \mathrm{SD}}\end{array}$} & \multirow{2}{*}{$\begin{array}{c}\begin{array}{c}\text { Glucose in CSF* } \\
(\mathrm{mmol} / \mathrm{L})\end{array} \\
\text { Mean } \pm \mathrm{SD}\end{array}$} \\
\hline & Mean $\pm S D$ & Range & & & \\
\hline Meningitis & $7.2 \pm 4.6$ & $0.3-15.8$ & $10 / 4$ & $0.205 \pm 0.104$ & $3.52 \pm 0.65$ \\
\hline No meningitis & $8.3 \pm 6.3$ & $0.1-13.5$ & $4 / 4$ & $0.206 \pm 0.088$ & $3.66 \pm 1.00$ \\
\hline
\end{tabular}

* CSF, cerebrospinal fluid. 


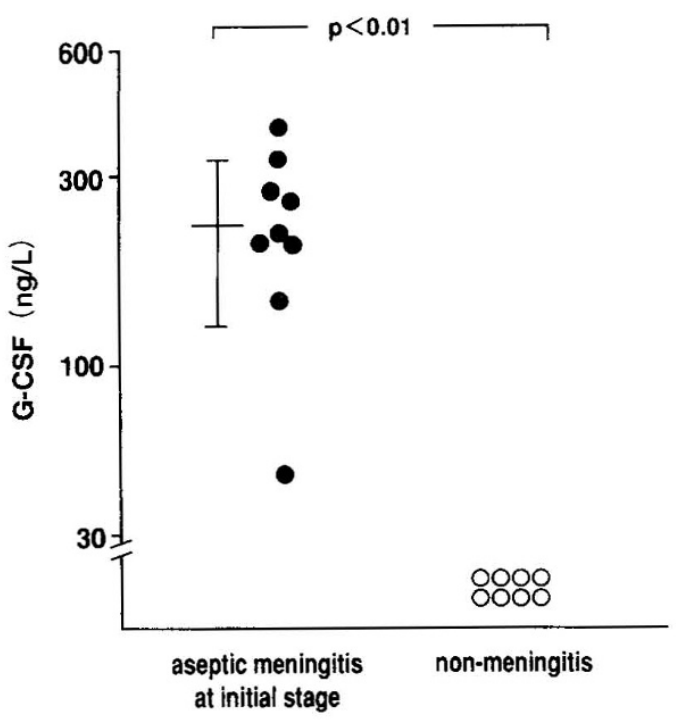

Figure 1. Levels of G-CSF in the cerebrospinal fluid of the patients within the first $2 \mathrm{~d}$ of onset of aseptic meningitis (-) and the patients without meningitis (O). The horizontal bar shows mean and the vertical bar shows SD in the meningitis group.

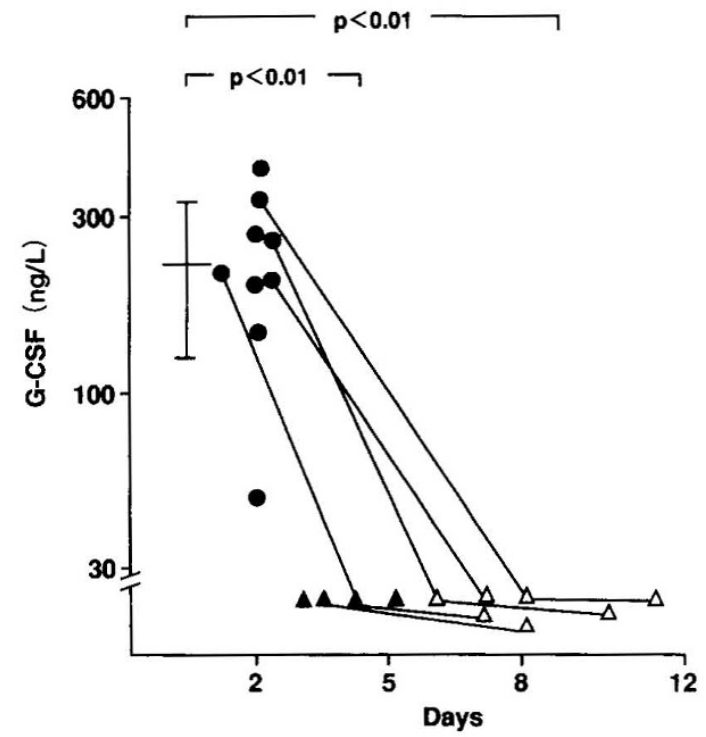

Figure 2. Levels of G-CSF in the cerebrospinal fluid from the onset of meningeal symptoms. Black symbols represent samples from the patients with meningeal signs or symptoms, and open symbols represent those without meningeal signs and symptoms. Circles represent samples within the first $2 \mathrm{~d}$ of aseptic meningitis, and triangles represent those after the second day. The horizontal bar shows mean and the vertical bar shows SD of black circles. Tie bars connect the samples of the same patients.

within the first $2 \mathrm{~d}$ of the illness were significantly higher than those after the second day $(p<0.01)$.

G-CSF levels in sera. G-CSF was not detectable in any serum samples except for one patient's sample, which had 33 $\mathrm{ng} / \mathrm{L}$ on the second day of the illness. The G-CSF levels of sera were statistically lower $(p<0.01)$ than those of the cerebrospinal fluid on any day of the disease in each patient (Table 2).

Neutrophil counts in the cerebrospinal fluid. Within the first $2 \mathrm{~d}$ of the illness, neutrophil counts increased (range 6 to 148 per $\mu \mathrm{L}$ ) in the cerebrospinal fluid of all patients (Fig. 3) and particularly accounted for the majority of cells in six of
Table 2. G-CSF levels in cerebrospinal fluid and serum in aseptic meningitis

\begin{tabular}{cccc}
\hline Within first 2 d & $\begin{array}{c}\text { After second day } \\
\text { with signs or } \\
\text { symptoms }\end{array}$ & $\begin{array}{c}\text { After second day } \\
\text { without signs or } \\
\text { symptoms }\end{array}$ \\
\hline CSF $^{*}$ & $\begin{array}{c}223 \pm 9.7 \dagger \\
(n=9)\end{array}$ & $<30(n=4)$ & $<30(n=7)$ \\
Serum & $33(n=1)$ & $<30(n=3)$ & $<30(n=3)$ \\
& $<30(n=5)$ & & \\
\hline
\end{tabular}

Values are expressed in $\mathrm{ng} / \mathrm{L}$ of $\mathrm{G}-\mathrm{CSF}$.

* CSF, cerebrospinal fluid.

$\dagger$ Value is represented as mean \pm SD. G-CSF levels are statistically higher in the cerebrospinal fluid than in the serum $(p<0.01)$.

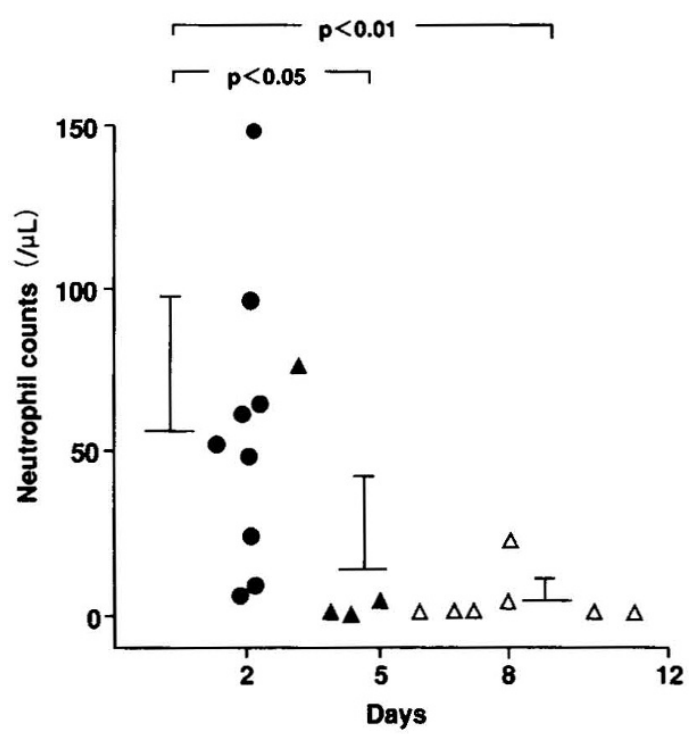

Figure 3. Neutrophil counts in the cerebrospinal fluid of the patients with aseptic meningitis. Black symbols represent samples from the patients with meningeal signs or symptoms, and open symbols represent those without meningeal signs and symptoms. Circles represent samples taken within the first $2 \mathrm{~d}$ of the illness, and triangles represent those taken after the second day. Horizontal bars show means and vertical bars show SD in each group.

nine patients. After the fourth day of the disease, neutrophils disappeared rapidly and were replaced by mononuclear cells.

Relationship between G-CSF levels and clinical indices. Figure 4 shows the relationship between the G-CSF levels and neutrophil counts in the cerebrospinal fluid of the patients. At the initial stage of the disease, both G-CSF levels and neutrophil counts increased. Thereafter, neutrophils disappeared from the cerebrospinal fluid as G-CSF levels decreased. There was a direct relationship between G-CSF levels and neutrophil counts $(r=0.763, p<0.01)$. However, no distinct correlation was found between G-CSF levels and mononuclear cell counts in the cerebrospinal fluid $(r=-0.446, p>0.05)$. The G-CSF concentrations in the cerebrospinal fluid did not correlate with either the level or duration of fever, headache, or vomiting; glucose levels; or protein values in the cerebrospinal fluid.

\section{DISCUSSION}

We have investigated whether G-CSF levels correlate with neutrophil counts in the cerebrospinal fluid in aseptic meningitis, paying particular attention to their changes in the course of the disease. The G-CSF levels in the cerebrospinal fluid 


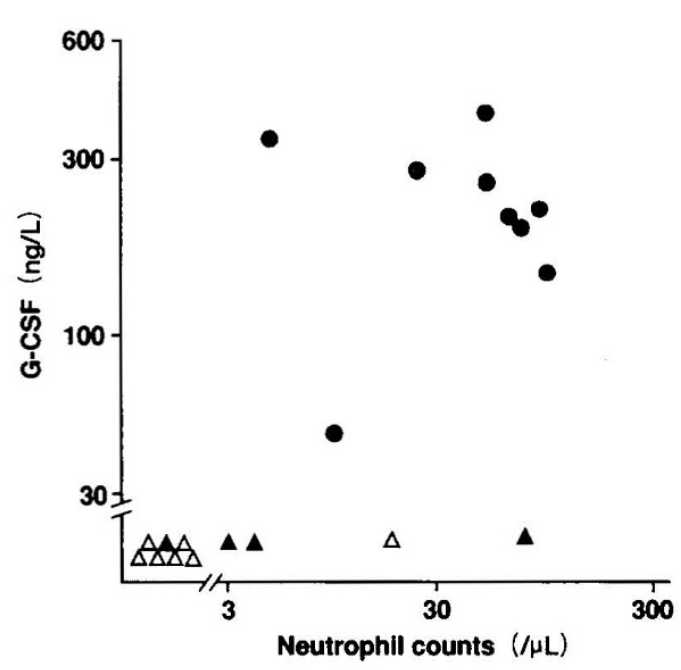

Figure 4. Relationship between the level of G-CSF and neutrophil counts in the cerebrospinal fluid of the patients. For all values, the Pearson's correlation coefficient is $0.763(p<0.01)$. Black symbols represent samples from the patients with meningeal signs or symptoms, and open symbols represent those without meningeal signs and symptoms. Circles represent samples taken within the first $2 \mathrm{~d}$ of the illness, and triangles represent those taken after the second day.

significantly increased at the initial stage of aseptic meningitis. However, on and after the third day of the illness, the G-CSF levels decreased rapidly to points below sensitivity ( $<30 \mathrm{ng}$ ) $\mathrm{L})$, regardless of the presence of any meningeal sign or symptom. It is now clear that in cases of aseptic meningitis G-CSF does not vanish from the cerebrospinal fluid with the disappearance of meningeal signs and symptoms; rather, it appears only during the initial stage of the illness.

Shimoda et al. (25) have reported a rise in the level of G-CSF in the cerebrospinal fluid in $12(67 \%)$ of 18 cases of aseptic meningitis. In contrast, we have found elevation of the G-CSF levels in every case during the first $2 \mathrm{~d}$. Although sensitivity of measurement was almost the same in both of the assays (their sensitivity level was $20 \mathrm{ng} / \mathrm{L}$ ), the frequency of G-CSF elevation in their subjects seems lower than in ours. We did not detect G-CSF in any patient whom we first punctured after the second day from onset. They did not present the data of G-CSF kinetics in the cerebrospinal fluid in aseptic meningitis. Inasmuch as the G-CSF levels in aseptic meningitis decreased rapidly during the first $3 \mathrm{~d}$ after onset, they may not have found G-CSF elevation in any of their subjects.

We next studied how G-CSF increased in the cerebrospinal fluid of patients with aseptic meningitis. At the initial stage, G-CSF levels in the cerebrospinal fluid were remarkably higher than those in the serum at the same time in each case. Serum G-CSF levels did not fluctuate during the progression of the illness. These results suggest that elevated levels of G-CSF in the cerebrospinal fluid were not caused by a switch over from the blood but rather by its production in the focus of inflammation, i.e. in the spinal cavity. Monocytes/macrophages (26$28)$, endothelial cells $(29,30)$, and fibroblasts $(31,32)$ produce G-CSF. Astrocytes (33-35) also produce G-CSF in the CNS. It is reported that IL- $1 \beta(36)$, IL-6 $(37,38), \operatorname{IFN}-\gamma(38)$, and GM-CSF (39), but not tumor necrosis factor- $\alpha(36,40)$, in the cerebrospinal fluid are increased in aseptic meningitis. IL- $1 \beta$ can stimulate fibroblasts (32), endothelial cells $(29,30)$, and astrocytes $(33,35)$ and GM-CSF can stimulate monocytes/ macrophages (28) to produce G-CSF in vitro. It is unlikely that endotoxin stimulates production of G-CSF in aseptic meningitis. Taken together, we assume there are cytokine networks in the CNS: IL-1 $\beta$ and GM-CSF induced by viral infection might stimulate fibroblasts, endothelial cells, monocytes/macrophages, and astrocytes to produce G-CSF.

We analyzed the relationship in the cerebrospinal fluid between the G-CSF levels and neutrophil counts. As is well known, neutrophils increase transiently during the initial stage of the illness. In our studies, both the G-CSF levels and neutrophil counts rose in the cerebrospinal fluid at the initial stage, and afterward the neutrophil counts decreased along with the drop in the G-CSF levels. G-CSF can augment migration of mature neutrophils (16). We conjecture that the G-CSF increasing in the cerebrospinal fluid can induce mobilization of neutrophils out of the peripheral blood and into the spinal cavity. It deserves discussion why the appearance of neutrophils in the cerebrospinal fluid takes place only during the initial stage of the illness. The plasma terminal half-life of rhG-CSF is $7.2 \pm 3.7 \mathrm{~h}$ when G-CSF is injected i.v. at 100 , 200,400 , and $800 \mu \mathrm{g} / \mathrm{m}^{2}$ (41). This short half-life of G-CSF causes rapid disappearance once G-CSF production stops in the focus of inflammation. Furthermore, the period of viral proliferation in the meninges seems to be short, and there is no endotoxin present as a strong stimulator of G-CSF production in the cerebrospinal fluid in viral infection. In any event, it is likely that such a rapid change in the G-CSF levels results in transient increases in the neutrophil counts in the cerebrospinal fluid during only the initial stage of aseptic meningitis.

Activated mature neutrophils produce chemical agents, including leukotrienes, IFN, etc. (42). Inasmuch as leukotriene $\mathrm{B}_{4}$ increases vascular permeability and develops inflammatory reactions, it can lead to the subsequent migration of lymphocytes into the spinal cavity. IFN also may act as a defense mechanism against viruses. However, additional studies are necessary to elucidate the exact pathophysiologic significance of the transient increase in neutrophils in the cerebrospinal fluid along with elevation of G-CSF levels.

Pleocytosis is an index for meningitis. However, it is difficult at the initial stage to distinguish aseptic meningitis from purulent meningitis by neutrophil counts alone. G-CSF in the cerebrospinal fluid increases in aseptic meningitis. The peak levels reach $386 \mathrm{ng} / \mathrm{L}$ as shown in our study or $366 \mathrm{ng} / \mathrm{L}$ as reported by others (25). We also measured G-CSF levels in the cerebrospinal fluid in a case of pneumococcal purulent meningitis. The G-CSF levels were $4700 \mathrm{ng} / \mathrm{L}$ on the third day of illness, $111 \mathrm{ng} / \mathrm{L}$ on the fifth day, and below sensitivity on the seventh day, when meningeal symptoms had disappeared. Shimoda et al. (25) reported that G-CSF levels in the cerebrospinal fluid markedly increased and averaged $1500 \mathrm{ng} / \mathrm{L}$ in 10 of 11 cases of purulent meningitis. These levels - in both their investigation (25) and ours-in patients with purulent meningitis were significantly higher $(p<0.05)$ than those in our patients with aseptic meningitis. In five of their subjects (25), the G-CSF values dropped below sensitivity after the disappearance of meningeal symptoms. The highly elevated levels 
of G-CSF persist for a long time, probably because an endotoxin derived from bacteria exists as a powerful stimulating factor of G-CSF production. The extremely high levels of G-CSF in the cerebrospinal fluid over $560 \mathrm{ng} / \mathrm{L}$ (mean +3.5 $\mathrm{SD}$ in our patients with aseptic meningitis) may be suggestive of purulent meningitis. Furthermore, disappearance of G-CSF from the cerebrospinal fluid within a few days may allow us to suppose aseptic meningitis. Taken together, G-CSF levels in the cerebrospinal fluid may be a useful index of meningitis. We look forward to the development of a rapid and simple method to assay G-CSF levels.

Acknowledgments. The authors thank Professor Atsushi Komiyama, Department of Pediatrics, Shinshu University School of Medicine, Matsumoto, for his encouragement and critical suggestions throughout this work. We also thank the staff of Applied Research Laboratories, Chugai Pharmaceutical Co., Ltd., Tokyo, for their support.

\section{REFERENCES}

1. Cherry JD 1992 Acute aseptic meningitis. In: Behrman RE, Kliegman RM, Nelson WE, Vaughan VC (eds) Nelson Textbook of Pediatrics, 14th Ed. WB Saunders, Philadelphia, pp 664-666

2. Burgess AW, Metcalf D 1980 The nature and action of granulocyte-macrophage colony-stimulating factors. Blood 56:947-958

3. Welte K, Platzer E, Lu L, Gabrilove JL, Levi E, Mertelsmann R, Moore MAS 1985 Purification and biological characterization of human pluripotent hematopoietic colony-stimulating factor. Proc Natl Acad Sci USA 82:1526-1530

4. Souza LM, Boone TC, Gabrilove J, Lai PH, Zsebo KM, Murdock DC, Chazin VR, Bruszewski J, Lu H, Chen KK, Barendt J, Platzer E, Moore MAS, Mertelsmann R, Welte K 1986 Recombinant human granulocyte colony-stimulating factor: effects on normal and leukemic myeloid cells. Science 232:61-65

5. Metcalf D 1987 The molecular control of normal and leukaemic granulocyte and macrophages. Proc R Soc Lond (Biol) 230:389-423

6. Gabrilove JL 1988 Biological effects and clinical applications of human colony stimulating factors. In: Pinedo HM, Longo DL, Chabner BA (eds) Cancer Chemotherapy and Biological Response Modifiers, Annual 10. Elsevier, Amsterdam, pp 492-506

7. Whetton $\mathrm{AD}$, Dexter TM 1989 Myeloid haemopoietic growth factors. Biochim Biophys Acta 989:111-132

8. Crosier PS, Clark SC 1992 Basic biology of hematopoietic growth factor. Semin Oncol 19:349-361

9. Yuo A, Kitagawa S, Ohsaka A, Ohta M, Miyazono K, Okabe T, Urabe A, Saito M, Takaku F 1989 Recombinant human granulocyte colony-stimulating factor as an activator of human granulocytes: potentiation of responses triggered by receptormediated agonists and stimulation of C3bi receptor expression and adherence. Blood $74: 2144-2149$

10. Nathan CF 1989 Respiratory burst in adherent human neutrophils: triggering by colony-stimulating factors CSF-GM and CSF-G. Blood 73:301-306

11. Kitagawa S, Yuo A, Souza LM, Saito M, Miura Y, Takaku F 1987 Recombinant human granulocyte colony-stimulating factor enhances superoxide release in human granulocytes stimulated by the chemotactic peptide. Biochem Biophys Res Commun 144:1143-1146

12. Yuo A, Kitagawa S, Okabe T, Urabe A, Komatsu Y, Itoh S, Takaku F 1987 Recombinant human granulocyte colony-stimulating factor repairs the abnormalities of neutrophils in patients with myelodysplastic syndromes and chronic myelogenous leukemia. Blood 70:404-411

13. Roilides E, Walsh TJ, Pizzo PA, Rubin M 1991 Granulocyte colony-stimulating factor enhances the phagocytic and bactericidal activity of normal and defective human neutrophils. J Infect Dis 163:579-583

14. Lopez AF, Nicola NA, Burgess AW, Metcalf D, Battye FL, Sewell WA, Vadas M 1983 Activation of granulocyte cytotoxic function by purified mouse colonystimulating factors. J Immunol 131:2983-2988

15. Vadas MA, Nicola NA, Metcalf D 1983 Activation of antibody-dependent cellmediated cytotoxicity of human neutrophils and eosinophils by separate colonystimulating factors. J Immunol 130:795-799

16. Wang JM, Chen ZG, Colella S, Bonilla MA, Welte K, Bordignon C, Mantovani A 1988 Chemotactic activity of recombinant human granulocyte colony-stimulating factor. Blood 72:1456-1460

17. Begley CG, Lopez AF, Nicola NA, Warren DJ, Vadas MA, Sanderson CJ, Metcalf D 1986 Purified colony-stimulating factors enhance the survival of human neutrophils and eosinophils in vitro: a rapid and sensitive microassay for colony-stimulating factors. Blood 68:162-166
18. Colotta F, Re F, Polentarutti N, Sozzani S, Mantovani A 1992 Modulation of granulocyte survival and programmed cell death by cytokines and bacterial products. Blood 80:2012-2020

19. Watari K, Asano S, Shirafuji N, Kodo H, Ozawa K, Takaku F, Kamachi S 1989 Serum granulocyte colony-stimulating factor levels in healthy volunteers and patients with various disorders as estimated by enzyme immunoassay. Blood 73:117-122

20. Kawakami M, Tsutsumi H, Kumakawa T, Abe H, Hirai M, Kurosawa S, Mori M, Fukushima M 1990 Levels of serum granulocyte colony-stimulating factor in patients with infections. Blood 76:1962-1964

21. Metcalf D 1985 The granulocyte-macrophage colony-stimulating factors. Science 229:16-22

22. Weisbart RH, Gasson JC, Golde DW 1989 Colony-stimulating factors and hos defense. Ann Intern Med 110:297-303

22a.Numazaki Y, Oshima T, Ohmi A, Tanaka A, Oizumi Y, Komatsu S, Takagi T, Karahasi M, Ishida N 1987 A microplate method for isolation of viruses from infant and children with acute respiratory infections. Microbiol Immunol 31:1085-1095

23. Motojima H, Kobayashi T, Shimane M, Kamachi S, Fukushima M 1989 Quantitative enzyme immunoassay for human granulocyte colony stimulating factor (G-CSF). J Immunol Methods 118:187-192

24. Nagata S, Tsuchiya M, Asano S, Kaziro Y, Yamazaki T, Yamamoto O, Hirata Y, Kubota N, Oheda M, Nomura H, Ono M 1986 Molecular cloning an expression of cDNA for human granulocyte colony-stimulating factor. Nature 319:415-418

25. Shimoda K, Okamura S, Omori F, Mizuno Y, Hara T, Aoki T, Ueda K, Niho Y 1991 Granulocyte colony-stimulating factor in cerebrospinal fluid from patients with meningitis. Blood 77:2214-2217

26. Lu L, Walker D, Graham CD, Waheed A, Shadduck RK, Broxmeyer HE 1988 Enhancement of release from MHC class II antigen-positive monocytes of hematopoietic colony stimulating factors CSF-1 and G-CSF by recombinant human tumor necrosis factor-alpha: synergism with recombinant human interferon-gamma. Blood $72: 34-41$

27. Vellenga E, Rambaldi A, Ernst TJ, Ostapovicz D, Griffin JD 1988 Independent regulation of M-CSF and G-CSF gene expression in human monocytes. Blood 71:1529-1532

28. Oster W, Lindemann A, Mertelsmann R, Herrmann F 1989 Granulocyte-macrophage colony-stimulating factor (CSF) and multilineage CSF recruit human monocytes to express granulocyte CSF. Blood 73:64-67

29. Broudy VC, Kaushansky K, Harlan JM, Adamson JW 1987 Interleukin 1 stimulates human endothelial cells to produce granulocyte-macrophage colony-stimulating factor and granulocyte colony-stimulating factor. J Immunol 139:464-468

30. Zsebo KM, Yuschenkoff VN, Schiffer S, Chang D, McCall E, Dinarello CA, Brown MA, Altrock B, Bagby GC 1988 Vascular endothelial cells and granulopoiesis: interleukin-1 stimulates release of G-CSF and GM-CSF. Blood 71:99-103

31. Koeffler HP, Gasson J, Ranyard J, Souza L, Shepard M, Munker R 1987 Recombinan human TNF $\alpha$ stimulates production of granulocyte colony-stimulating factor. Blood 70:55-59

32. Kaushansky K, Lin N, Adamson JW 1988 Interleukin 1 stimulates fibroblasts to synthesize granulocyte-macrophage and granulocyte colony-stimulating factors: Mechanism for the hematopoietic response to inflammation. J Clin Invest 81:92-97

33. Tweardy DJ, Mott PL, Glazer EW 1990 Monokine modulation of human astroglia cell production of granulocyte colony-stimulating factor and granulocyte-macrophage colony-stimulating factor: I. Effects of IL-1 $\alpha$ and IL-1 $\beta$. J Immunol 144:2233-2241

34. Malipiero UV, Frei K, Fontana A 1990 Production of hemopoietic colony-stimulating factors by astrocytes. J Immunol 144:3816-3821

35. Aloisi F, Care A, Borsellino G, Gallo P, Rosa S, Bassani A, Cabibbo A, Testa U, Levi G, Peschle C 1992 Production of hemolymphopoietic cytokines (IL-6, IL-8, colonystimulating factors) by normal human astrocytes in response to $\mathrm{IL}-1 \beta$ and tumor necrosis factor- $\alpha$. J Immunol 149:2358-2366

36. Ramilo O, Mustafa MM, Porter J, Saez-Llorens X, Mertsola J, Olsen KD, Luby JP, Beutler B, McCracken GH 1990 Detection of interleukin $1 \beta$ but not tumor necrosis factor- $\alpha$ in cerebrospinal fluid of children with aseptic meningitis. Am J Dis Child 144:349-352

37. Fukushima $\mathrm{K}$, Ishiguro A, Nakamura T, Suzuki Y, Nagayama S, Abe M, Umezawa T, Nakahata T, Komiyama A, Shimbo T 1993 Elevated levels of interleukin 6 in the cerebrospinal fluid in childhood aseptic meningitis (in Japanese with English summary). Jpn J Inflammation 13:263-268

38. Frei K, Leist TP, Meager A, Gallo P, Leppert D, Zinkernagel RM, Fontana A 1988 Production of B cell stimulatory factor- 2 and interferon in the central nervous system during viral meningitis and encephalitis: evaluation in a murine model infection and in patients. J Exp Med 168:449-453

39. Shimoda K, Okamura S, Omori F, Mizuno Y, Hara T, Aoki T, Akeda H, Ueda K, Niho Y 1991 Detection of granulocyte-macrophage colony-stimulating factor in cerebrospinal fluid of patients with aseptic meningitis. Acta Haematol 86:36-39

40. Nadal D, Leppert D, Frei K, Gallo P, Lamche H, Fontana A 1989 Tumor necrosi factor- $\alpha$ in infectious meningitis. Arch Dis Child 64:1274-1279

41. Eguchi K, Sasaki S, Tamura T, Sasaki Y, Shinkai T, Yamada K, Soejima Y, Fukuda M, Fujihara Y, Kunitou H, Tobinai K, Ohtsu T, Suemasu K, Takaku F, Saijo N 1989 Dose escalation study of recombinant human granulocyte-colony-stimulating facto (KRN8601) in patients with advanced malignancy. Cancer Res 49:5221-5224

42. Borgeat P, Samuelsson B 1979 Arachidonic acid metabolism in polymorphonuclear leukocytes: unstable intermediate in formation of dihydroxy acids. Proc Natl Acad Sci USA 76:3213-3217 